Journal of Mathematics and Statistics 6 (4): 395-408, 2010

ISSN 1549-3644

(C) 2010 Science Publications

\title{
Symmetry of Nonparametric Statistical Tests on Three Samples
}

\author{
${ }^{1}$ Anna E. Bargagliotti and ${ }^{2}$ Donald G. Saari \\ ${ }^{1}$ Department of Mathematical Sciences University of Memphis, \\ 366 Dunn Hall, Memphis, TN 38152 \\ ${ }^{2}$ Department of Mathematics and Department of Economics, \\ Institute for Mathematical Behavioral Sciences, University of California, \\ Irvine CA 92697-5100
}

\begin{abstract}
Problem statement: Many different nonparametric statistical procedures can be used to analyze ranked data. Inconsistencies among the outcomes of such procedures can occur when analyzing the same ranked data set. Understanding why these peculiarities can occur is imperative to providing an accurate analysis of the ranking data. In this context, this study addressed why inconsistent outcomes can occur and which types of data structures cause the different procedures to yield different outcomes. Approach: Appropriate properties were identified and developed to explain why different methods can define different rankings of three samples with the same data. The approach identifies certain symmetry structures that are implicitly contained within the data and analyzes how the procedures utilize these structures to produce an outcome. Results: We proved that all possible differences among the nonparametric rules are caused because different rules place different levels of emphasis on the specified symmetry configurations of data. Our findings explain and characterize why different procedures can output different results using the same data set. Conclusion: This study therefore served as crucial step in deciding which nonparametric procedure to use when analyzing ranked data. In addition, it serves as the building block to defining new techniques to analyze rankings. Because different procedures use different aspects of the data in different ways, then one may determine the choice of analysis procedure based on what parts of the data one deems important.
\end{abstract}

Key words: Nonparametric, symmetry, ranked data, Kruskal-Wallis

\section{INTRODUCTION}

As it is known, the peculiarities of different nonparametric tests can complicate the choice of an appropriate test statistic. To shed light on this concern, we identify those features of nonparametric procedures that cause dissimilar, even conflicting results to occur with the same data set. Our approach uses the fact that, before noticeable differences can arise in the tests, disagreements can be expected among the implicit rankings that are defined by the associated procedures. For instance, before a disagreement can occur between the Kruskal and Wallis (1952) and, say, the Bhapkar (1961) tests, we should anticipate differences in how the $\mathrm{k}$ samples are ranked as implicitly determined by the Kruskal-Wallis and the Bhapkar V procedures. Thus it is natural to analyze these more sensitive ranking behaviors to understand why these differences can arise.

The way we do so is to extract certain hidden symmetry structures that are implicitly defined by the data. The value of discovering these structures is that they identify and completely characterize which data configurations force different classes of nonparametric procedures to have different outcomes. As an illustration of what our analysis provides, consider the interesting mystery coming from the following ranked data set for three alternatives $\{\mathrm{A}, \mathrm{B}, \mathrm{C}$,$\} :$

$\begin{array}{ccc}\text { A } & \text { B } & \text { C } \\ 12 & 11 & 10 \\ 7 & 9 & 8 \\ 5 & 4 & 6 \\ 2 & 1 & 3\end{array}$

For these data, the Kruskal-Wallis procedure leads to the $\mathrm{C} \succ \mathrm{A} \succ \mathrm{B}$ ranking while these same data force the Bhapkar (1961) procedure to yield the $\mathrm{A} \succ \mathrm{B} \succ \mathrm{C}$ ranking. The data structures that will be identified in our analysis completely explain all such behavior of

Corresponding Author: Anna E. Bargagliotti, Department of Mathematical Sciences, University of Memphis, 366 Dunn Hall, Memphis, TN 38152 
this kind. As another illustration using this data set, the Wilcoxon (1945) rules (denoted by MWW) define the $\mathrm{A} \succ \mathrm{B}, \mathrm{B} \sim \mathrm{C}, \mathrm{C} \succ \mathrm{A}$ rankings of the pairs. Again, our analysis completely explains how and why all such differences can arise, it shows that all possible differences are due how different rules react to a particular symmetry structure of the data.

By knowing which kinds of data configurations cause rules to have different outcomes, we obtain a deeper understanding about the behaviors and peculiarities of various nonparametric tests. If, for instance, a certain data structure that is not viewed as being important turns out to influence the tallies and rankings of a specified procedure, then the associated test may not be an appropriate one. Conversely, if one rule ignores a type of data structure that is accepted as being valuable while a second one does not, then this information provides support for adopting the second rule. For example, the data presented above, lead the Kruskal-Wallis test to reject the null hypothesis at the 0.05 significance level, the $\mathrm{V}$ test to reject the null hypothesis at the 0.01 significance level and the MannWhitney test to fail to reject the null for all pair wise comparisons of the three alternatives. Thus the data configurations developed here highlight the precise structures of the data that can lead to an inference decision with some test but not others. This, in turn, directly affects the choice of nonparametric test to be used in an analysis.

As we will show, all possible differences among these rules are in terms of how they react to these hidden symmetry components of the data. Namely, some procedures ignore certain symmetries that are inherent in the data, while the outcomes of other rules are strongly influenced by them. What complicates the analysis is that these symmetries are not apparent within data sets. Fortunately, however, the symmetries can be identified at an intermediate step in the processing of the data and so our analysis extracts the symmetry structures from this intermediate step.

As described in the Materials and Methods, this intermediate step is where the nonparametric methods over $\mathrm{k}$ sample-the ones we have in mind-combine data information into k-tuples. In a natural manner, identify this space of $\mathrm{k}$-tuples with a Euclidean space $\mathbb{R}^{\mathrm{k}}$, this identification makes it possible to associate the symmetries of $\mathbb{R}^{\mathrm{k}}$ with those of the k-tuples and to determine how these symmetries affect different nonparametric procedures. (Our approach is influenced by recent results in decision analysis, e.g., Saari, 2008).

By identifying the symmetry structures and their consequences at the intermediate step, it becomes possible to define an "imposed symmetry structure" for data sets. For instance, after we prove that a particular symmetry structure at the intermediate stage causes all differences between the Kruskal-Wallis ranking and pair wise comparisons, we then describe how this symmetry is manifested within the data.

\section{MATERIALS AND METHODS}

Our method for uncovering why different procedures may yield different results when analyzing the same ranked data, consists of three steps: (1) translate a raw data set to triples, (2) define and decompose how a nonparametric procedure utilizes the triples information and (3) define symmetries (e.g., rotational, inversion) on the data space to uncover how different procedures react to such structures. In this study, we describe each of the steps in detail.

From data to triplets: For purposes of clarity, our analysis emphasizes the three-sample setting denoted by the three alternatives A, B, C; for convenience, assume that a data set of $\mathrm{n}$ items is collected for each alternative. An item may be, for example, the temperature of a chemical, or the bending strength of a material sample. List the information as in the following array of raw, unranked data:

$$
\begin{array}{ccc}
A & B & C \\
r_{1} & s_{1} & t_{1} \\
r_{2} & s_{2} & t_{2} \\
\cdots & \cdots & \cdots \\
r_{n} & s_{n} & t_{n}
\end{array}
$$

Replace these values with integers ranging from 1$3 n$, which indicate how a value ranks across all samples, smaller numbers correspond to lower temperatures, or a weaker bending strength. This creates the following equation of ranked data (denote the space by RD):

$$
\begin{array}{ccc}
A & B & C \\
a_{1} & b_{1} & c_{1} \\
a_{2} & b_{2} & c_{2} \\
\cdots & \cdots & \cdots \\
a_{n} & b_{n} & c_{n}
\end{array}
$$

where, the $a_{j}, b_{k}, c_{s}$ terms are the ranking integers that range from 1 to $3 \mathrm{n}$.

The ranked data in a Eq. 1 form is converted into triplets by listing all $\mathrm{n}^{3}$ triplets $\left(\mathrm{a}_{\mid}, \mathrm{b}_{\mathrm{k}}, \mathrm{c}_{\mathrm{m}}\right)$. To replace each triplet with a ranking, make a distinction as to 
whether larger or smaller values are "better," in this article, larger values as treated as being more preferred. In the case of an unbalanced design, the number of triplets will not equal $\mathrm{n}^{3}$, however, the conversion of data into triplets remains the same as the balanced case. Denote this space of ranked triplets by TS. Represent this process as a mapping (Haunsperger, 1992):

$$
\mathrm{G}: \mathrm{RD} \rightarrow \mathrm{TS}
$$

As an illustrating example, the following ranked data set from RD:

$$
\mathrm{d}=\begin{array}{lll}
\mathrm{A} & \mathrm{B} & \mathrm{C} \\
6 & 5 & 4 \\
1 & 2 & 3
\end{array}
$$

defines the eight triplets:

$$
(6,5,4),(6,5,3),(6,2,4),(6,2,3),(1,5,4),(1,5,3),(1,2,4),(1,2,3)
$$

With, respectively, the associated rankings:

$$
\begin{aligned}
& \mathrm{A} \succ \mathrm{B} \succ \mathrm{C}, \mathrm{A} \succ \mathrm{B} \succ \mathrm{C}, \mathrm{A} \succ \mathrm{C} \succ \mathrm{B}, \mathrm{A} \succ \mathrm{C} \succ \mathrm{B}, \\
& \mathrm{B} \succ \mathrm{C} \succ \mathrm{A}, \mathrm{B} \succ \mathrm{C} \succ \mathrm{A}, \mathrm{C} \succ \mathrm{B} \succ \mathrm{A}, \mathrm{C} \succ \mathrm{B} \succ \mathrm{A}
\end{aligned}
$$

Thus, $\mathrm{G}(\mathrm{d})$ is the set of eight rankings with two each of $\mathrm{A} \succ \mathrm{B} \succ \mathrm{C}, \mathrm{C} \succ \mathrm{B} \succ \mathrm{A}, \mathrm{A} \succ \mathrm{C} \succ \mathrm{B}$ and $\mathrm{B} \succ \mathrm{C} \succ \mathrm{A}$.

There are six ways to strictly rank triplets, so TS resides in a six-dimensional space, each of the six rankings define a $\mathbb{R}^{6}$ coordinate direction. By choosing the $\mathbb{R}^{6}$ coordinate directions in the:

$$
\begin{aligned}
& \mathrm{A} \succ \mathrm{B} \succ \mathrm{C}, \mathrm{A} \succ \mathrm{C} \succ \mathrm{B}, \mathrm{C} \succ \mathrm{A} \succ \mathrm{B}, \mathrm{C} \succ \mathrm{B} \succ \mathrm{A}, \\
& \mathrm{B} \succ \mathrm{C} \succ \mathrm{A}, \mathrm{B} \succ \mathrm{A} \succ \mathrm{C}
\end{aligned}
$$

order, the triplets associated with the above $\mathrm{d}$ can be expressed as $\mathrm{G}(\mathrm{d})=(2,2,0,2,2,0)$. Ties are handled in an obvious $\mathbb{R}^{6}$ manner, e.g., a triplet with the $\mathrm{A} \sim \mathrm{B} \succ \mathrm{C}$ ranking splits the difference between $\mathrm{A} \succ \mathrm{B} \succ \mathrm{C}$ and $\mathrm{B} \succ \mathrm{A} \succ \mathrm{C}$ with $(1 / 2,0,0,0,0,1 / 2)$, while $\mathrm{A} \sim \mathrm{B} \sim \mathrm{C}$ is represented by $(1 / 6, \ldots, 1 / 6)$. For large values of $n$, the standard analysis can become computationally intensive. As such, representing the data as an element in $\mathbb{R}^{6}$ greatly condenses the information captured by the data. Moreover, because all computations reduce to dot products of vectors, this $\mathbb{R}^{6}$ representation provides an efficient, simpler way to explore the data set's important features.

A class of nonparametric rules: The nonparametric rules considered here include pair wise comparison tests such as the Wilcoxon rank sum test and MannWhitney test as well as k sample comparison tests for the one-way layout.

The $\mathrm{k}$ sample comparison procedures that we consider create a ranking by assigning points to each alternative based on how it is ranked within each ktuple, or, in our setting, within each triplet.

Members of this class of procedures have been proposed by Bhapkar (1961); Deshpande (1970) and Bhapkar and Deshpande (1968). With the Bhapkar V test, for instance, an alternative receives a point for each triplet in which it is top-ranked. In contrast, the Bhapkar and Deshpande (1968) procedure assigns +1 points to an alternative each time it is top-ranked in a ktuple and -1 points for each time it is bottom-ranked. While the Kruskal-Wallis test normally sums the ranks assigned to each alternative, Haunsperger (1992) showed that the ranking also arises by assigning an alternative two points for each triplet where it is topranked and one point for each triplet where it is secondranked. While the use of some of these tests is not as widespread as, say, the Kruskal-Wallis approach, it is important to include the full class of these procedures in our analysis in order to understand the features that cause different tests to have different outcomes. In this manner, new insights are obtained about subtle, hidden features of approaches, such as that of Kruskal-Wallis.

As our objective is to identify what causes different procedures to have differences in the rankings and tallies over three samples, we can, without loss of generality, use the fact that these rankings are invariant with respect to affine changes in the assigned weights. This permits us to assume that the bottom ranked alternative always receives zero points. So, if a rule assigns 3, 0 and -1 points to an alternative each time it is, respectively, top, middle and bottom ranked in a triplet, an equivalent rule is obtained by adding one point to each weight so that the assigned values now are $(4,1,0)$. Next, scale the assigned points so that one point is assigned to the top-ranked alternative, e.g., the $(4,1,0)$ choice becomes $(1,1 / 4,0)$.

In this manner, any three sample rule can be represented by $(1, \mathrm{~s}, 0)$ for a specific value of $\mathrm{s} \in[0,1]$. As an illustration, the normalized weights assigned to the Bhapkar V test are $(1,0,0)$. With the BhapkarDeshpande rule involving $\mathrm{k}$ samples, the original weights of the $(1,0, \ldots, 0,-1)$ choice are translated to $(2$, $1, \ldots, 1,0)$ and then scaled to $(1,1 / 2, \ldots, 1 / 2,0)$. Thus, for triplets, the normalized weights for BhapkarDeshpande rule agree with the Kruskal-Wallis rule's normalized weights of $(1,1 / 2,0)$. 
Decomposition of the procedures: The rule ranks the alternatives in terms of the sums of the assigned points. Let the summation process for a procedure that uses the weights $(1, s, 0), s \in[0,1]$ be represented by the mapping

$\mathrm{P}_{\mathrm{s}}: \mathrm{TS} \rightarrow \mathbb{R}^{3}$

where, the tallies are listed in the A, B, C order. To illustrate with the above $\mathrm{p}=(2,2,0,2,2,0)$, which represents the Eq. 3 data, we have:

$\mathrm{P}_{\mathrm{s}}(\mathrm{p})=\left(4,2+4_{\mathrm{s}}, 2+4_{\mathrm{s}}\right)$

where, the tallies are listed in the A, B, C order, e.g., A receives 4 points while $B$ and $C$ each receive $2+4 \mathrm{~s}$ points. Notice how the choice of $s$ alters the final ranking, for instance, with $s<\frac{1}{2}$, A has a higher score than $\mathrm{B}$, with $\mathrm{s}>\frac{1}{2}$, $\mathrm{B}$ has a higher score than $\mathrm{A}$ and with $s=\frac{1}{2}$, which corresponds to the Kruskal-Wallis procedure, all alternatives have the same tally.

With these choices, a class of nonparametric rules can be written as a composition of functions in the following manner (Haunsperger, 1992).

Definition: For a specified value of $s$ satisfying $0 \leq s \leq 1$ and ranked data $\mathrm{d}, \mathrm{NP}_{\mathrm{s}}$ is the nonparametric procedure defined as:

$\mathrm{NP}_{\mathrm{s}}(\mathrm{d})=\mathrm{P}_{\mathrm{s}}(\mathrm{G}(\mathrm{d}))$

For example, $\mathrm{NP}_{1}$ and $\mathrm{NP}_{\frac{1}{2}}$ represent, respectively, the Bhapkar V and the Kruskal-Wallis procedures. With the Eq. 3 choice of d, it follows from Eq. 6 that the Bhapkar $\mathrm{V}$ ranking is $\mathrm{A} \sim \mathrm{C} \succ \mathrm{B}$ while the KruskalWallis ranking is $\mathrm{A} \sim \mathrm{B} \sim \mathrm{C}$ :

The MWW rankings of binaries have a similar representation. Namely, let:

$$
\mathrm{B}_{\mathrm{X}, \mathrm{Y}}: \mathrm{TS} \rightarrow \mathbb{R}^{2}
$$

be the mapping where the first component registers the number of triplets for which $\mathrm{X}$ is ranked above $\mathrm{Y}$ and the second component registers the number of triplets for which $\mathrm{Y}$ is ranked above $\mathrm{X}$. The MWW rankings defined by a data set $d$ for the pair $\{X, Y\}$ is given by the composition $\mathrm{B}_{\mathrm{X}, \mathrm{Y}}(\mathrm{G}(\mathrm{d}))$.

Symmetries of the TS space: The symmetries for three samples come from $\mathrm{S}_{3}$-the space of all ways to permute three alternatives. Three of these symmetry configurations are natural, an explanation for the fourth is given later.

The first and obvious symmetry configuration of TS is an orbit of $S_{3}$, this configuration of triplets has each ranking occurring the same number of times. If $\mathrm{K}$ $=(1,1,1,1,1,1)$, then, for an appropriate choice of c $>0$, this configuration is represented by $\mathrm{cK}$. Obviously, this configuration of $6 \mathrm{c}$ triplets leads to tie rankings for all of the $\mathrm{P}_{\mathrm{s}}$ rules and for all pairwise comparisons, as such, $\mathrm{cK}$ is called a kernel configuration.

The next natural symmetry is the $\mathbb{Z}_{3}$ orbit of a triplet. For instance, if the starting ranking is $\mathrm{A} \succ \mathrm{B} \succ \mathrm{C}$, then the set defined by the $\mathbb{Z}_{3}$ orbit is:

$\{\mathrm{A} \succ \mathrm{B} \succ \mathrm{C}, \mathrm{B} \succ \mathrm{C} \succ \mathrm{A}, \mathrm{C} \succ \mathrm{A} \succ \mathrm{B}\}$.

This particular rotational configuration consisting of three triplets has the $(1,0,1,0,1,0) \in \mathbb{R}^{6}$ vector representation. The other rotational triplet, generated by $\mathrm{A} \succ \mathrm{C} \succ \mathrm{B}$, is given by $(0,1,0,1,0,1)$. To construct either configuration of preferences, move the top ranked alternative in one triplet to the bottom ranking in the next triplet. This construction ensures that each alternative is in first, second and third place precisely once over the set of three triplets.

A final natural symmetry is the $Z_{2}$ orbit, this pair consists of the ranking of a triplet and the inverted version of the ranking. As an illustration, the $\mathbb{Z}_{2}$ orbit of the ranking $\mathrm{A} \succ \mathrm{B} \succ \mathrm{C}$ is the set $\{\mathrm{A} \succ \mathrm{B} \succ \mathrm{C}, \mathrm{C} \succ \mathrm{B} \succ \mathrm{A}\}$. For alternative $\mathrm{X}, \mathrm{X}=\mathrm{A}, \mathrm{B}, \mathrm{C}$, an $\mathrm{X}$-inversion configuration, $\mathrm{I}_{\mathrm{X}}$, consists of the four different triplets where $\mathrm{X}$ is either top or bottom ranked: As such, $\mathrm{X}$ is top ranked for two of the triplets and $\mathrm{X}$ is bottom ranked for each of the two remaining triplets. Using the vector representation, the $\mathrm{A}$-inversion configuration is $\mathrm{I}_{\mathrm{A}}=(1,1,0,1,1,0)$, while the $\mathrm{B}$-inversion configuration is $I_{B}=(0,1,1,0,1,1)$. Notice that the Eq. 4 configuration is $p=2 \mathrm{I}_{\mathrm{A}}$.

What remains is what we call the core configuration, it consists of six triplets. The configuration for an alternative $\mathrm{X}$ is where there are two triplets for each ranking where $\mathrm{X}$ is top-ranked and there is a single triplet for each ranking where $\mathrm{X}$ is middle-ranked. Thus, $\mathrm{C}_{\mathrm{A}}=(2,2,1,0,0,1)$, while $\mathrm{C}_{\mathrm{B}}=$ $(1,0,0,1,2,2)$.

\section{RESULTS}

As the tests for these various rules are based on the tallies of $\mathrm{NP}_{\mathrm{s}}(\mathrm{d})=\mathrm{P}_{\mathrm{s}}(\mathrm{G}(\mathrm{d}))$ and as the $\mathrm{G}(\mathrm{d})$ value is common for all tests, it follows that all differences in 
tests are due to differences in the $\mathrm{P}_{\mathrm{s}}$ tallies. This observation, combined with our concern to understand what causes all possible differences in these tallies and rankings, shifts the emphasis to determine how the symmetry structures of the TS space, or $\mathbb{R}^{6}$, affect the different $\mathrm{P}_{\mathrm{s}}$ outcomes. This analysis is carried out in results. Then, to capture how this symmetry structure is manifested by data, we develop an argument to capture aspects of the inverse image of $\mathrm{G}$.

Our main results are summarized below in Theorem 1. The Theorem characterizes how each nonparametric procedure utilizes the symmetry configurations in the ranking data. The role of these configurations of triplets is captured by the following theorem, which, de facto, describes a coordinate system for the vector space TS (to ensure that the system is partially orthogonal, the above choices are slightly modified in what follows). The value gained by using this coordinate system is that, as shown in Theorem 1, the coordinates separate the components of $G(d) \in T S$ into those parts that cause different nonparametric procedures to have different tallies and rankings.

Theorem 1: Let $\mathrm{X}, \mathrm{Y}, \mathrm{Z}$ represent the three alternatives:

1. The space of triplets, TS, is spanned by the kernel, rotational, inversion and core configurations

2. The kernel configurations provide ties for all $P_{\mathrm{s}}$ and $\mathrm{B}_{\mathrm{X}, \mathrm{Y}}$ outcomes

3. With a rotational configuration, all $\mathrm{P}_{\mathrm{s}}$ mappings yield a completely tied outcome. However, the $\mathrm{B}_{\mathrm{X}, \mathrm{Y}}, \mathrm{B}_{\mathrm{Y}, \mathrm{Z}}, \mathrm{B}_{\mathrm{Z}, \mathrm{X}}$ outcomes form a cycle where, for each pair, the tally is the same

4. For any inversion configuration, the outcome for any pair $B_{X, Y}$ is a tie. For the $P_{s}$ rankings, the Kruskal-Wallis procedure, $\mathrm{P}_{\frac{1}{2}}$, has a tie. For the other rules, the rankings of all $\mathrm{P}_{\mathrm{s}}$ for $\mathrm{s}<\frac{1}{2}$ are the opposite of the rankings for $\mathrm{P}_{\mathrm{s}}$ for $\mathrm{s}>\frac{1}{2}$

5. For any core configuration of triplets, all $\mathrm{P}_{\mathrm{s}}$ rankings agree and all $\mathrm{B}_{\mathrm{X}, \mathrm{Y}}$ rankings agree with this common $\mathrm{P}_{\mathrm{s}}$ ranking

The importance of this result, which is described in more detail below, is that these symmetry configurations fully determine why different nonparametric procedures have different outcomes and rankings. As an illustration, notice that all Ps outcomes agree on the core configurations, this assertion requires any disagreements among different $\mathrm{P}_{\mathrm{s}}$ procedures and tests to be caused by the data components that create inversion configurations. Thus this theorem (and Eq. 7) provides a complete explanation for all possible differences in rankings between, say, the Bhapkar $\mathrm{V}$ and the Kruskal-Wallis procedures. Namely, rankings for the Bhapkar V test are influenced by the triplets with inversion components, but the Kruskal-Wallis procedure ignores these components.

This assertion can be illustrated with the Eq. 3 data set d. Using Eq. 7, the $\mathrm{V}$ procedure ranking is the $\mathrm{P}_{1}$ outcome of $2 \mathrm{I}_{\mathrm{A}}$, which is $(2,1,1)$ with the corresponding $\mathrm{A} \succ \mathrm{B} \sim \mathrm{C}$ ranking. As the Kruskal-Wallis ranking ignores this inversion structure, it must yield the complete tie $\mathrm{A} \sim \mathrm{B} \sim \mathrm{C}$.

Similarly, according to Theorem 1, all differences in rankings between the Kruskal-Wallis procedure and paired comparisons are caused by the rotational components. Thus, if the data does not have components of triplets of this kind, the Kruskal-Wallis and MWW rankings of the pairs completely agree, even the tallies can be obtained from each other. But if $G(d)$ does have rotational components, differences emerge at least in the tallies if not the rankings.

It remains to describe the core configurations: they are found in the following manner. According to part 1 of Theorem 1, the kernel, rotational and inversion configurations define a four dimensional linear subspace of six-dimensional TS space. The remaining two-dimensional orthogonal subspace is spanned by the core configurations. While the construction comes from linear algebra, a surprise is the universal consistency of outcomes for all procedures over these configurations.

Proof 1: To prove 1, first modify these configurations so that they create a coordinate system, to do so only require removing kernel components from each choice to make the result orthogonal to any kernel vector. For instance, the rotational triplet $2 \mathrm{R}=(2,0,2,0,2,0)$ represents six triplets, it consists of two sets of the Eq. 8 rankings. To convert this vector into a form that is orthogonal to the kernel configuration $\mathrm{K}=(1,1,1,1,1,1)$, use:

$$
\begin{aligned}
\tilde{\mathrm{R}} & =2 \mathrm{R}-\mathrm{K}=(2,0,2,0,2,0)-(1,1,1,1,1,1) \\
& =(1,-1,1,-1,1,-1)
\end{aligned}
$$

where, the +1 terms define one rotational triplet and the -1 terms define the other one. The interpretation of a negative value in a configuration, then, is to subtract this number of triplets when $\tilde{R}$ is added to a specified set of triplets.

The resulting coordinate system defined for the sixdimensional TS consists of the kernel vector $\mathrm{K}$, the rotational coordinate $\tilde{\mathrm{R}}$ of Eq. 9, a two-dimensional space spanned by the modified inversion profiles: 
$\tilde{\mathrm{I}}_{\mathrm{A}}=3 \mathrm{I}_{\mathrm{A}}-2 \mathrm{~K}=(1,1,-2,1,1,-2), \tilde{\mathrm{I}}_{\mathrm{B}}=(-2,1,1,-2,1,1)$

and the two-dimensional space spanned by the modified core configurations:

$$
\tilde{\mathrm{C}}_{\mathrm{A}}=(1,1,0,-1,-1,0), \tilde{\mathrm{C}}_{\mathrm{B}}=(0,-1,-1,0,1,1) \text {. }
$$

A computation proves that $\tilde{\mathrm{I}}_{\mathrm{A}}+\tilde{\mathrm{I}}_{\mathrm{B}}+\tilde{\mathrm{I}}_{\mathrm{C}}=0$, which means that the inversion configurations form a twodimensional space. Similarly, $\tilde{\mathrm{C}}_{\mathrm{A}}+\tilde{\mathrm{C}}_{\mathrm{B}}+\tilde{\mathrm{C}}_{\mathrm{C}}=0$ proves the two-dimensional assertion about the core configurations. A direct computation shows that the four different subspaces are orthogonal to each other. As these six vectors are independent, they span R6.

Proof 2: This is obvious.

Proof 3: For a rotational configuration, say $(1,0,1,0$, $1,0)$, each alternative is in first, second and third place over the three triplets. Thus the outcomes for all $\mathrm{P}_{\mathrm{s}}$ rules is a complete tie. As the same is true for $(0,1,0,1,0,1)$ and as $\mathrm{P}_{\mathrm{s}}$ is a linear mapping, the assertion follows.

For the rotational configuration $\mathrm{R}=(1,0,1,0,1$, 0 ), a tally shows that $\mathrm{B}_{\mathrm{A}, \mathrm{B}}(\mathrm{R})=\mathrm{B}_{\mathrm{B}, \mathrm{C}}(\mathrm{R})=\mathrm{B}_{\mathrm{C}, \mathrm{A}}(\mathrm{R})=$ (2,1), which yields the asserted $\mathrm{A} \succ \mathrm{B}, \mathrm{B} \succ \mathrm{C}, \mathrm{C} \succ \mathrm{A}$ cyclic rankings. The reversed cycle occurs with $(0,1,0$, $1,0,1)$. More generally, a computation proves that:

$$
\mathrm{B}_{\mathrm{A}, \mathrm{B}}(\tilde{\mathrm{R}})=(1,-1), \mathrm{B}_{\mathrm{B}, \mathrm{C}}(\tilde{\mathrm{R}})=(1,-1), \mathrm{B}_{\mathrm{C}, \mathrm{A}}(\tilde{\mathrm{R}})=(1,-1)
$$

The name of this configuration reflects this rotational effect of the paired comparison rankings.

Proof of 4: The proof involves a computation. An inversion configuration consists of two triplets with opposite rankings, such as $\mathrm{A} \succ \mathrm{B} \succ \mathrm{C}$ and $\mathrm{C} \succ \mathrm{B} \succ \mathrm{A}$. Thus, the ranking of a specified pair in the first triplet is accompanied by the opposite ranking of the same pair in the second triplet. The pair wise cancellation requires all $\mathrm{B}_{\mathrm{X}, \mathrm{Y}}$ rankings to be ties over inversion configurations.

The situation changes over the Ps mappings because $\mathrm{P}_{\mathrm{s}}\left(\mathrm{I}_{\mathrm{A}}\right)=(2,1+2 \mathrm{~s}, 1+2 \mathrm{~s})$ while $\mathrm{P}_{\mathrm{s}}\left(\mathrm{I}_{\mathrm{B}}\right)=(1+$ $2 s, 2,1+2 s)$. As any inversion configuration can be expressed as $\mathrm{aI}_{\mathrm{A}}+\mathrm{bI}_{\mathrm{B}}$, where $\mathrm{a}$ and $\mathrm{b}$ are scalars, it follows that:

$\mathrm{P}_{\mathrm{s}}\left(\mathrm{aI}_{\mathrm{A}}+\mathrm{bI}_{\mathrm{B}}\right)=(2 \mathrm{a}+\mathrm{b}(1+2 \mathrm{~s}), \mathrm{a}(1+2 \mathrm{~s})+2 \mathrm{bs},(\mathrm{a}+\mathrm{b})(1+2 \mathrm{~s}))$

When $\mathrm{s}=\frac{1}{2}$, the outcome is, as asserted, the complete tie $(2(a+b), 2(a+b), 2(a+b))$.
To prove the second part of the assertion, notice that Eq. 13 is linear in $s$ and $s=\frac{1}{2}$ is a complete tie. Thus, to prove that the rankings for $s<\frac{1}{2}$ are the opposite of the rankings for $\mathrm{s}>\frac{1}{2}$, it suffices to examine what happens at the extremes of $s=0$ and $s=1$. These tallies are, respectively, $(2 a+b, 2 b+a, a+b)$ and $(2 a+3 b$, $2 b+3 a, 3(a+b))$. So, if the $s=0$ ranking has $A>B$, then $2 a+b>2 b+a$, or $a>b$. (With algebra, it now follows that the same $\mathrm{P}_{\mathrm{s}}$ ranking holds for $\mathrm{s}<\frac{1}{2}$.) Conversely, the $\mathrm{s}$ $=1$ ranking of this pair, given by the $2 a+3 b$ and $3 a+2 b$ tallies, has B>A. (Again, by use of algebra, it follows that the same $\mathrm{P}_{\mathrm{s}}$ ranking holds for $\mathrm{s}>\frac{1}{2}$.) A similar algebraic computation holds if $\mathrm{B}>\mathrm{A}$ and for the $\{\mathrm{A}, \mathrm{C}\}$ and $\{B, C\}$ pairs.

Proof 5: By using the linearity of the $P_{s}$ and $B_{X, Y}$ mappings, it suffices to prove that the assertion holds for the basis vectors of TS, i.e., the core configurations $\mathrm{C}_{\mathrm{A}}$ and $\mathrm{C}_{\mathrm{B}}$. With the core configuration $\mathrm{C}_{\mathrm{A}}=(2,2,1,0$, $0,1)$, we have that:

$$
\mathrm{P}_{\mathrm{S}}\left(\mathrm{C}_{\mathrm{A}}\right)=(4,1,1)+2_{\mathrm{s}}(1,1,1)
$$

so all $\mathrm{P}_{\mathrm{s}}$ values agree modulo an inflation term of $2 \mathrm{~s}(1,1,1)$. By using $\tilde{\mathrm{C}}_{\mathrm{x}}$ instead of $\mathrm{C}_{\mathrm{x}}$, it becomes apparent that $(2+2 s)(1,1,1)$ reflects a kernel effect, this is because:

$\mathrm{P}_{\mathrm{s}}\left(\tilde{\mathrm{C}}_{\mathrm{A}}\right)=(2,-1,-1)$

where, no $\mathrm{s}$ terms arise. Similarly, $\mathrm{B}_{\mathrm{A}, \mathrm{B}}\left(\mathrm{C}_{\mathrm{A}}\right)=$ $\mathrm{B}_{\mathrm{A}, \mathrm{C}}\left(\mathrm{C}_{\mathrm{A}}\right)=(5,1), \quad \mathrm{B}_{\mathrm{B}, \mathrm{C}}\left(\mathrm{C}_{\mathrm{A}}\right)=(3,3)$. The close connection with the Ps values becomes clear by subtracting $(3,3)$ from each value, this is the same as computing $\mathrm{B}_{\mathrm{A}, \mathrm{B}}\left(\tilde{\mathrm{C}}_{\mathrm{A}}\right)=\mathrm{B}_{\mathrm{A}, \mathrm{C}}\left(\tilde{\mathrm{C}}_{\mathrm{A}}\right)=(2,-2), \mathrm{B}_{\mathrm{B}, \mathrm{C}}\left(\tilde{\mathrm{C}}_{\mathrm{A}}\right)=(0,0)$. The conclusion follows.

Theorem 2: For three alternatives, a simultaneous complete tie for any two $\mathrm{NP}_{\mathrm{s}}(\mathrm{d})$ rules and all pair wise comparisons occurs if and only if $\mathrm{G}(\mathrm{d})$ is a kernel configuration and there is a complete tie for all NPs rules.

Suppose for $\mathrm{s}_{1} \neq \mathrm{s}_{2}$ that the rankings for both $\mathrm{NP}_{\mathrm{s} 1}(\mathrm{~d})$ and $\mathrm{NP}_{\mathrm{s} 2}(\mathrm{~d})$ are complete ties, but there is at least one non-tied pair wise comparison. This situation occurs if and only if all $\mathrm{NP}_{\mathrm{s}}(\mathrm{d})$ rankings define a 
complete tie and the three pair wise comparisons define a cycle (where the difference in tallies is the same for each pair). In this setting, G(d) is the sum of kernel and rotational triplets.

Suppose all pair wise comparisons end in complete ties, but for at least one $\mathrm{s} \neq \frac{1}{2}$, the $\mathrm{NP}_{\mathrm{s}}(\mathrm{d})$ ranking is not a complete tie. This situation occurs if and only if the Kruskal-Wallis ranking is a complete tie and the rankings for all $\mathrm{NP}_{\mathrm{s}}(\mathrm{d}), \mathrm{s} \neq \frac{1}{2}$, are not ties. The $\mathrm{G}(\mathrm{d})$ outcome of triplets strictly consists of a kernel configuration plus a linear combination of inversion configurations. In this setting, the $\mathrm{NP}_{\mathrm{s}}(\mathrm{d})$ ranking for $\mathrm{s}<\frac{1}{2}$ must be the reversal of the $\mathrm{NP}_{\mathrm{s}}(\mathrm{d})$ ranking for $\mathrm{s}>\frac{1}{2}$.

\section{DISCUSSION}

In this study, we discuss several consequences to the results presented above. We further explore their implications and illustrate that the symmetric data structures are the cause of all differences in nonparametric procedures. In addition, we develop the theory further to show how one can uncover the symmetry structures in a particular data set. Ultimately, our discussion leads us to characterizing the features that data must satisfy in order to contain such structures.

Consequences: According to Theorem 1, all possible differences in $\mathrm{NP}_{\mathrm{s}}(\mathrm{d})$ rankings can be identified and explained strictly by how the associated $\mathrm{P}_{\mathrm{s}}$ mappings react to the different components of the $G(d)$ list of triplets. The starting point for data set $d \in R D$ is the core component of $\mathrm{G}(\mathrm{d})$, here the rankings for all nonparametric rules and all pair wise comparisons agree and all differences in tallying values are due to the values the different rules assign to kernel components.

An immediate consequence of this assertion is that all differences among the rankings and tallies of the different procedures are strictly caused by the inversion and rotational components of $\mathrm{G}(\mathrm{d})$. This means, for example, that any and all differences among $\mathrm{NP}_{\mathrm{s}}$ rules, as well as the outcomes of the associated tests, are caused by the inversion component of $\mathrm{G}(\mathrm{d})$. The only rule that is not affected by these components is $\mathrm{NP}_{\frac{1}{2}}$, which is the Kruskal-Wallis rule. This result means that if the configurations of such inversion effects are not viewed as being important, then the Kruskal-Wallis rule should be adopted over any other $\mathrm{NP}_{\mathrm{s}}, \mathrm{s} \neq \frac{1}{2}$ method. If, however, the information content of such configurations is treated as being valuable, then one of the $\mathrm{NP}_{\mathrm{s}}, \mathrm{s} \neq \frac{1}{2}$ rules should be adopted. The exact choice depends on what is desired for an $\mathrm{A} \succ \mathrm{B} \succ \mathrm{C}$, $\mathrm{C} \succ \mathrm{B} \succ \mathrm{A}$ configuration.

Similarly, all possible differences between the Kruskal-Wallis procedure and pair wise comparisons are due to how these different rules react to rotational components of $\mathrm{G}(\mathrm{d})$, the Kruskal-Wallis procedure ignores this information, while the pair wise comparisons are affected by it. For other $\mathrm{NP}_{\mathrm{s}}$ rules, $\mathrm{s} \neq \frac{1}{2}$, differences in the tallies and rankings with pair wise comparisons are caused by a combination of the rotational and inversion components of $\mathrm{G}(\mathrm{d})$. In other words, all difficulties and complexities caused by paired comparison rankings are strictly due to the cyclic component of $G(d)$. No other term plays a role.

In the other direction and by use of Theorem 1 , information about the structure of the data set $d$ and the $\mathrm{G}(\mathrm{d})$ triplets can be obtained from the $\mathrm{NP}_{\mathrm{s}}(\mathrm{d})$ rankings. Some of these results are captured in Theorem 2. Notice, for instance, that situations exist where it is impossible to have a single non-tied paired comparison.

Summary of the consequences of data structure: The above results permit us to completely characterize which data structures affect the different nonparametric tests. This structure completely explains why different procedures have different outcomes. More specifically:

- The Kruskal-Wallis procedure is strictly determined by the portion of ranked data that defines the core component in $\mathrm{G}(\mathrm{d})$. Non-core components-the inversion and rotational configurations-have no effect on the KruskalWallis ranking

- For $\mathrm{s} \neq \frac{1}{2}$, the $\mathrm{NP}_{\mathrm{s}}$ outcome is determined strictly by the components of the ranked data that create the core and inversion components of the $\mathrm{G}(\mathrm{d})$ profile, the rotational component has no impact on this ranking. For the data portion creating a core 
component, the $\mathrm{NP}_{\mathrm{s}}$ rule agrees with the KruskalWallis outcome. All possible differences occur by how different $\mathrm{NP}_{\mathrm{s}}$ rules react to the inversion components in $\mathrm{G}(\mathrm{d})$. These $\mathrm{NP}_{\mathrm{s}}$ outcomes define a line in $\mathbb{R}^{3}$ centered around the Kruskal-Wallis outcome. (According to Eq. 7, the score for each alternative is the number of times it is top-ranked plus $s$ times the number of times it is secondranked. With three alternatives and $0 \leq s \leq 1$, this defines a line in $\mathbb{R}^{3}$, e.g., the proof of Theorem 2 )

- $\quad$ All MWW rankings of pairs are strictly determined by the data portions that introduce core and the rotational components in $\mathrm{G}(\mathrm{d})$. The outcome over the core component agrees with the Kruskal-Wallis outcome. All other differences are created by the cyclic effect introduced by the rotational component of a $\mathrm{G}(\mathrm{d})$ profile

According to this description, cycles of paired comparison rankings, different $\mathrm{NP}_{\mathrm{s}}$ rankings and differences among the pair wise and $\mathrm{NP}_{\mathrm{s}}$ rankings occur because the outcomes for different rules rely on different portions of the data structure. The results are stated for the case where $\mathrm{k}=3$ where the concepts are easily understandable, however, the ideas presented extend to $\mathrm{k}>3$, but by using different symmetries.

Data structures: Now that the source of all differences in nonparametric procedures are understood, the next step is to understand what kinds of d data structures create the different symmetry components of $G(d)$. The first step is to find a representation that captures the different $G(d)$ components and then to use this representation to develop intuition about the various forms of data.

Finding the symmetry components: The decomposition of $\mathrm{G}(\mathrm{d})$ can be described with a matrix. First, let $\mathrm{p} \in \mathbb{R}^{6}$ be a vector and let $\hat{\mathrm{P}}=\left(\mathrm{a}_{\mathrm{C}}, \mathrm{b}_{\mathrm{C}}, \mathrm{a}_{\mathrm{I}}, \mathrm{b}_{\mathrm{I}}, \mathrm{r}\right.$, $\mathrm{k}$ ) be the representation of $\mathrm{p}$ in terms of the coordinate system:

$$
\tilde{\mathrm{C}}_{\mathrm{A}}, \tilde{\mathrm{C}}_{\mathrm{B}}, \tilde{\mathrm{I}}_{\mathrm{A}}, \tilde{\mathrm{I}}_{\mathrm{B}}, \tilde{\mathrm{R}}, \mathrm{K} .
$$

Namely, $\tilde{\mathrm{P}}=\mathrm{A}_{\mathrm{C}} \tilde{\mathrm{C}}_{\mathrm{a}}+\mathrm{b}_{\mathrm{c}} \tilde{\mathrm{C}}_{\mathrm{a}}+\mathrm{a}_{\mathrm{I}} \tilde{\mathrm{I}}_{\mathrm{A}}+\mathrm{b}_{\mathrm{I}} \tilde{\mathrm{I}}_{\mathrm{B}}+\mathrm{r} \tilde{\mathrm{R}}+\mathrm{kK}$.

By using the $\mathbb{R}^{6}$ vector representations of these Eq. 15 coordinates, which are given in Eq. 9-11, the matrix relationship between $\mathrm{p}$ and $\tilde{\mathrm{P}}$ is:

$\mathrm{p}=\mathrm{A}\left(\hat{\mathrm{p}}^{\mathrm{t}}\right), \mathrm{A}=\left(\tilde{\mathrm{C}}_{\mathrm{A}}^{\mathrm{t}}, \tilde{\mathrm{C}}_{\mathrm{B}}^{\mathrm{t}}, \tilde{\mathrm{I}}_{\mathrm{A}}^{\mathrm{t}}, \tilde{\mathrm{I}}_{\mathrm{B}}^{\mathrm{t}}, \tilde{\mathrm{R}}^{\mathrm{t}}, \mathrm{K}^{\mathrm{t}}\right)$ where, the superscript " $t$ " designates the transpose, e.g., $\mathrm{p}^{\mathrm{t}}$ is the column version of $\mathrm{p}$.

As matrix $\mathrm{A}$ is nonsingular, it follows from matrix algebra that $\hat{\mathrm{p}}^{\mathrm{t}}=\mathrm{T}\left(\mathrm{p}^{\mathrm{t}}\right)$ where:

$$
\mathrm{T}=\mathrm{A}^{-1}=\frac{1}{6}\left(\begin{array}{cccccc}
2 & 1 & -1 & -2 & -1 & 1 \\
1 & -1 & -2 & -1 & 1 & 2 \\
0 & 1 & -1 & 0 & 1 & -1 \\
-1 & 1 & 0 & -1 & 1 & 0 \\
1 & -1 & 1 & -1 & 1 & -1 \\
1 & 1 & 1 & 1 & 1 & 1
\end{array}\right)
$$

Using the above described Eq. 3 ranked data as an illustration, this d leads to $\mathrm{G}(\mathrm{d})=\mathrm{p}=(2,2,0,2,2,0)$. Using this choice of $\mathrm{p}$ with $\mathrm{T}$, we obtain:

$$
\mathrm{T}\left(\begin{array}{l}
2 \\
2 \\
0 \\
2 \\
2 \\
0
\end{array}\right)=\left(\begin{array}{c}
0 \\
0 \\
\frac{2}{3} \\
0 \\
0 \\
\frac{4}{3}
\end{array}\right)
$$

or the $\hat{p}=\frac{2}{3} \hat{I}_{A}+\frac{4}{3} K=2 I_{A}$ representation.

Examples, the $\mathbf{n}=\mathbf{2}$ case: To appreciate how different ranked data structures cause $\mathrm{G}(\mathrm{d})$ to have different kinds of symmetry components, it is particularly useful to determine everything that can happen with three alternatives and $n=2$ (where the unranked data does not have ties). By completely cataloguing what can happen, we discover that, already in this simplest non-trivial setting, interesting differences among the different procedures emerge.

To reduce the number of possible cases, notice that the entries in each column of Eq. 1 can be permuted in any manner without affecting the triplets or G outcome. Thus, assume that each column is ranked from the largest value down to the smallest, e.g., $a_{j}>a_{j+1}$. As the names of the alternatives can be permuted, further assume that $\mathrm{a}_{1}>\mathrm{b}_{1}>\mathrm{c}_{1}$. Using these symmetries, the $\mathrm{n}=2$ setting is reduced from the original 6 ! possibilities to the following fifteen cases.

Theorem 3: The following ranked data sets define the associated profile decompositions, each decomposition also includes and $\frac{4}{3} \mathrm{~K}$ term: 


$$
\begin{aligned}
& \left(\begin{array}{lll}
6 & 5 & 4 \\
3 & 2 & 1
\end{array}\right) \rightarrow \frac{4}{3} \tilde{\mathrm{C}}_{\mathrm{A}}+\frac{2}{3}+\frac{2}{3} \tilde{\mathrm{C}}_{\mathrm{B}}-\frac{1}{3} \tilde{\mathrm{I}}_{\mathrm{B}}+\frac{2}{3} \tilde{\mathrm{R}}, \quad\left(\begin{array}{lll}
6 & 5 & 4 \\
1 & 2 & 3
\end{array}\right) \rightarrow \frac{2}{3} \tilde{\mathrm{I}}_{\mathrm{A}} \\
& \left(\begin{array}{lll}
6 & 5 & 4 \\
2 & 1 & 3
\end{array}\right) \rightarrow \frac{2}{3}\left[\tilde{\mathrm{C}}_{\mathrm{A}}-\tilde{\mathrm{C}}_{\mathrm{B}}-\tilde{\mathrm{I}}_{\mathrm{C}}\right]+\frac{2}{3} \tilde{\mathrm{R}}, \quad\left(\begin{array}{lll}
6 & 5 & 4 \\
1 & 3 & 2
\end{array}\right) \rightarrow \frac{1}{3}\left[\tilde{\mathrm{C}}_{\mathrm{B}}-\tilde{\mathrm{C}}_{\mathrm{C}}\right]+\frac{2}{3} \tilde{\mathrm{I}}_{\mathrm{A}}+\frac{2}{3} \tilde{\mathrm{R}}, \\
& \left(\begin{array}{ccc}
6 & 5 & 4 \\
2 & 3 & 1
\end{array}\right) \rightarrow \tilde{\mathrm{C}}_{\mathrm{A}}-\tilde{\mathrm{C}}_{\mathrm{B}}-\frac{1}{3} \tilde{\mathrm{I}}_{\mathrm{B}}, \quad\left(\begin{array}{lll}
6 & 5 & 4 \\
3 & 1 & 2
\end{array}\right) \rightarrow \tilde{\mathrm{C}}_{\mathrm{A}}+\frac{1}{3} \tilde{\mathrm{I}}_{\mathrm{A}}+\frac{1}{3} \tilde{\mathrm{I}}_{\mathrm{B}}, \\
& \left(\begin{array}{lll}
6 & 5 & 3 \\
1 & 4 & 2
\end{array}\right) \rightarrow \frac{2}{3} \tilde{\mathrm{C}}_{\mathrm{A}}+\frac{4}{3} \tilde{\mathrm{C}}_{\mathrm{B}}+\frac{2}{3} \tilde{\mathrm{I}}_{\mathrm{A}}+\frac{4}{3} \tilde{\mathrm{R}}, \quad\left(\begin{array}{lll}
6 & 5 & 3 \\
4 & 1 & 2
\end{array}\right) \rightarrow \tilde{\mathrm{C}}_{\mathrm{A}}+\tilde{\mathrm{I}}_{\mathrm{A}}+\frac{2}{3} \tilde{\mathrm{I}}_{\mathrm{B}} \\
& \left(\begin{array}{lll}
6 & 5 & 3 \\
2 & 4 & 1
\end{array}\right) \rightarrow \frac{4}{3} \tilde{\mathrm{C}}_{\mathrm{A}}+\frac{5}{3} \tilde{\mathrm{C}}_{\mathrm{B}}-\frac{1}{3} \tilde{\mathrm{I}}_{\mathrm{B}}+\frac{2}{3} \tilde{\mathrm{R}}, \quad\left(\begin{array}{lll}
6 & 5 & 3 \\
4 & 2 & 1
\end{array}\right) \rightarrow \frac{4}{3} \tilde{\mathrm{C}}_{\mathrm{A}}+\frac{2}{3} \tilde{\mathrm{C}}_{\mathrm{B}}-\frac{2}{3} \tilde{\mathrm{I}}_{\mathrm{A}}+\frac{2}{3} \tilde{\mathrm{R}} \\
& \left(\begin{array}{lll}
6 & 5 & 2 \\
3 & 4 & 1
\end{array}\right) \rightarrow 2 \tilde{\mathrm{C}}_{\mathrm{A}}+2 \tilde{\mathrm{C}}_{\mathrm{B}}-\frac{2}{3} \tilde{\mathrm{I}}_{\mathrm{A}}-\frac{2}{3} \tilde{\mathrm{I}}_{\mathrm{B}}, \quad\left(\begin{array}{lll}
6 & 5 & 2 \\
4 & 3 & 1
\end{array}\right) \rightarrow \frac{7}{3} \tilde{\mathrm{C}}_{\mathrm{A}}+\frac{5}{3} \tilde{\mathrm{C}}_{\mathrm{B}}-\frac{1}{3} \tilde{\mathrm{I}}_{\mathrm{A}}-\tilde{\mathrm{I}}_{\mathrm{B}}+\frac{2}{3} \tilde{\mathrm{R}}, \\
& \left(\begin{array}{lll}
6 & 4 & 3 \\
5 & 2 & 1
\end{array}\right) \rightarrow \frac{7}{3} \tilde{\mathrm{C}}_{\mathrm{A}}+\frac{2}{3} \tilde{\mathrm{C}}_{\mathrm{B}}-\frac{1}{3} \tilde{\mathrm{I}}_{\mathrm{A}}-\frac{2}{3} \tilde{\mathrm{I}}_{\mathrm{B}}+\frac{2}{3} \tilde{\mathrm{R}}, \quad\left(\begin{array}{lll}
6 & 4 & 3 \\
5 & 1 & 2
\end{array}\right) \rightarrow 2 \tilde{\mathrm{C}}_{\mathrm{A}}+\frac{2}{3} \tilde{\mathrm{I}}_{\mathrm{A}}, \\
& \left(\begin{array}{lll}
6 & 4 & 2 \\
5 & 3 & 1
\end{array}\right) \rightarrow \frac{8}{3} \tilde{\mathrm{C}}_{\mathrm{A}}+\frac{4}{3} \tilde{\mathrm{C}}_{\mathrm{B}}-\frac{4}{3} \tilde{\mathrm{I}}_{\mathrm{B}}+\frac{4}{3} \tilde{\mathrm{R}}
\end{aligned}
$$

As $\mathrm{K}$ consists of six triplets, the common $\frac{4}{3} \mathrm{~K}$ value means that each setting consists of $\frac{4}{3} 6=8$ triplets. To simplify the representations, some $\tilde{\mathrm{C}}_{\mathrm{A}}, \tilde{\mathrm{I}}_{\mathrm{A}}, \tilde{\mathrm{I}}_{\mathrm{B}}$ terms are replaced with $\tilde{\mathrm{C}}_{\mathrm{C}}$ and $\tilde{\mathrm{I}}_{\mathrm{C}}$ terms. The following statement explains how to find the $\tilde{\mathrm{C}}_{\mathrm{C}}$ and $\tilde{\mathrm{I}}_{\mathrm{C}}$ terms and it provides computational rules to quickly compute and compare outcomes.

Proposition 4: The coefficients for the core and inversion terms satisfy:

$$
\begin{aligned}
& \mathrm{a}_{\mathrm{C}} \tilde{\mathrm{C}}_{\mathrm{A}}+\mathrm{b}_{\mathrm{C}} \tilde{\mathrm{C}}_{\mathrm{B}}=\left(\mathrm{b}_{\mathrm{C}}-\mathrm{a}_{\mathrm{C}}\right) \tilde{\mathrm{C}}_{\mathrm{B}}-\mathrm{a}_{\mathrm{C}} \tilde{\mathrm{C}}_{\mathrm{C}} \\
& =\left(\mathrm{a}_{\mathrm{C}}-\mathrm{b}_{\mathrm{C}}\right) \tilde{\mathrm{C}}_{\mathrm{A}}-\mathrm{b}_{\mathrm{C}} \tilde{\mathrm{C}}_{\mathrm{C}} \mathrm{a}_{\mathrm{I}} \tilde{\mathrm{I}}_{\mathrm{A}}+\mathrm{b}_{\mathrm{I}} \tilde{\mathrm{I}}_{\mathrm{B}} \\
& =\left(\mathrm{b}_{\mathrm{I}}-\mathrm{a}_{\mathrm{I}}\right) \tilde{\mathrm{I}}_{\mathrm{B}}-\mathrm{a}_{\mathrm{I}} \tilde{\mathrm{I}}_{\mathrm{C}}=\left(\mathrm{a}_{\mathrm{I}}-\mathrm{b}_{\mathrm{I}}\right) \tilde{\mathrm{I}}_{\mathrm{A}}-\mathrm{b}_{\mathrm{I}} \tilde{\mathrm{I}}_{\mathrm{C}}
\end{aligned}
$$

The $\mathrm{P}_{\mathrm{s}}$ tally for $\tilde{\mathrm{C}}_{\mathrm{X}}$ assigns 2 points to $\mathrm{X}$ and -1 point to each of the other two alternatives. The Ps tally for $\tilde{I}_{\mathrm{X}}$ assigns $2-4 \mathrm{~s}$ points to $\mathrm{X}$ and $2 \mathrm{~s}-1$ points to each of the other alternatives. The Ps tally for K assigns $2+2$ s points to each alternative.

The tallies for $\tilde{C}_{\mathrm{X}}$ in an $\{\mathrm{X}, \mathrm{Y}\}$ pair wise comparison assign 2 points to $\mathrm{X}$ and -2 to $\mathrm{Y}$. In a pair not including $X$, both alternatives receive zero points. The tallies for pair wise comparisons with the rotational configuration $\tilde{\mathrm{R}}$ are A: B, B: C, C: A each by 1: -1 . The tallies of a pair for $\mathrm{K}$ assign three points to each alternative.

The Kruskal-Wallis ranking for A and B always agrees with the ranking of the scalars $\mathrm{a}_{\mathrm{C}}, \mathrm{b}_{\mathrm{C}}$. The $\mathrm{A}, \mathrm{C}$

ranking (respectively, $\mathrm{B}, \quad \mathrm{C}$ ranking) $\mathrm{A} \succ \mathrm{C}$ iff $\mathrm{a}_{\mathrm{C}}>0$ and $\mathrm{C} \succ \mathrm{A}$ iff $\mathrm{a}_{\mathrm{C}}>0 \quad$ (respectively, $\mathrm{B} \succ \mathrm{C}$ iff $\mathrm{b}_{\mathrm{C}}>0$ and $\mathrm{C} \succ \mathrm{B}$ iff $\mathrm{b}_{\mathrm{C}}>0$ ). If $\mathrm{A}_{\mathrm{T}}, \mathrm{B}_{\mathrm{T}}, \mathrm{C}_{\mathrm{T}}$ represent the Kruskal-Wallis tallies, then, with $b_{C} \neq 0$ :

$$
\frac{a_{c}-b_{c}}{b_{c}}=\frac{A_{T}-B_{T}}{B_{T}-C_{T}}
$$

Proof: The proof of Eq. 18 follows by using the appropriate substitutions of the two expressions $\tilde{\mathrm{C}}_{\mathrm{A}}+\tilde{\mathrm{C}}_{\mathrm{B}}+\tilde{\mathrm{C}}_{\mathrm{C}}=0$ and $\tilde{\mathrm{I}}_{\mathrm{A}}+\tilde{\mathrm{I}}_{\mathrm{B}}+\tilde{\mathrm{I}}_{\mathrm{C}}=0$.

The assertions about the tallies involve a direct computation.

To prove the material leading up to Eq. 19, notice that the Kruskal-Wallis tallies of $\mathrm{a}_{\mathrm{C}} \tilde{\mathrm{C}}_{\mathrm{A}}+\mathrm{b}_{\mathrm{C}} \tilde{\mathrm{C}}_{\mathrm{B}}$ for $\mathrm{A}, \mathrm{B}$, $\mathrm{C}$ are, respectively:

$4 \mathrm{a}_{\mathrm{C}}-2 \mathrm{~b}_{\mathrm{C}}, 4 \mathrm{~b}_{\mathrm{C}}-2 \mathrm{a}_{\mathrm{C}},-2\left(\mathrm{a}_{\mathrm{C}}+\mathrm{b}_{\mathrm{C}}\right)$

Thus, the $\quad \mathrm{A} \succeq \mathrm{B} \quad$ ranking occurs $4 a_{C}-2 b_{C} \geq 4 b_{C}-2 a_{C}$, or iff $a_{C} \geq b_{C}$. Similarly, the ranking $\mathrm{b}_{\mathrm{C}}>\mathrm{a}_{\mathrm{C}}$ holds iff $\mathrm{A} \succ \mathrm{B}$. The $\mathrm{A} \succ \mathrm{C}$ ranking occurs iff $4 a_{C}-2 b_{C}>-2 a_{C}-2 b_{C}$, or iff $a_{C}>0$, similarly, $\mathrm{C} \succ \mathrm{A}$ iff $\mathrm{a}_{\mathrm{C}}<0$. A similar expression in terms of the sign of $\mathrm{b}_{\mathrm{C}}$ holds for $\mathrm{B}, \mathrm{C}$ rankings.

To prove Eq. 19, notice that each of the $A_{T}, B_{T}, C_{T}$ Kruskal-Wallis tallies is a fixed multiple of the appropriate value in Eq. 20 plus a fixed constant (coming from the kernel term). Thus: 


$$
\frac{\mathrm{A}_{\mathrm{T}}-\mathrm{B}_{\mathrm{T}}}{\mathrm{B}_{\mathrm{T}}-\mathrm{C}_{\mathrm{T}}}=\frac{\left(4 \mathrm{a}_{\mathrm{C}}-2 \mathrm{~b}_{\mathrm{C}}\right)-\left(4 \mathrm{~b}_{\mathrm{C}}-2 \mathrm{a}_{\mathrm{C}}\right)}{\left(4 \mathrm{~b}_{\mathrm{C}}-2 \mathrm{a}_{\mathrm{C}}\right)\left(-2 \mathrm{a}_{\mathrm{C}}-2 \mathrm{~b}_{\mathrm{C}}\right)}=\frac{\mathrm{a}_{\mathrm{C}}-\mathrm{b}_{\mathrm{C}}}{\mathrm{b}_{\mathrm{C}}}
$$

Interestingly, six of the fifteen ranked data sets in Theorem 3 have no cyclic component: Thus over these sets the Kruskal-Wallis and the pair wise rankings completely agree (Theorem 1). But as all choices include inversion terms, it follows that for all three alternative, $\mathrm{n}=2$ settings, different $\mathrm{NP}_{\mathrm{s}}$ rules must have different tallies over the data sets, even the rankings may differ.

To illustrate Prop. 4 and Eq. 18 notice that $\left(\begin{array}{lll}6 & 5 & 4 \\ 1 & 3 & 2\end{array}\right)$ ranked data yields the $\frac{1}{3}\left[\tilde{\mathrm{C}}_{\mathrm{B}}-\tilde{\mathrm{C}}_{\mathrm{C}}\right]+\frac{2}{3} \tilde{\mathrm{I}}_{\mathrm{A}}+\frac{2}{3} \tilde{\mathrm{R}}+\frac{4}{3} \mathrm{~K}$ decomposition. According to Eq. 18, the core and inversion confidents are $c_{B}=\frac{1}{3}>c_{C}=-\frac{1}{3}$. By permuting the names in Prop. 4 so that $\mathrm{C}$ and $\mathrm{c}_{\mathrm{C}}$ assume the roles of $\mathrm{A}$ and $\mathrm{a}_{\mathrm{C}}$, we have that the Kruskal-Wallis ranking is $\mathrm{B} \succ \mathrm{A} \succ \mathrm{C}$. (The $\mathrm{B} \succ \mathrm{C}$ ranking follows from $\mathrm{c}_{\mathrm{B}}>\mathrm{c}_{\mathrm{C}}$, the $\mathrm{B} \succ$ A ranking follows from $b_{C}>0$ and the $A \succ C$ ranking follows from $\left.c_{C}<0\right)$. Moreover, because $\frac{c_{C}-b_{C}}{b_{C}}=-2$, we have that $\mathrm{B}_{\mathrm{T}}-\mathrm{C}_{\mathrm{T}}=2\left(\mathrm{~A}_{\mathrm{T}}-\mathrm{C}_{\mathrm{T}}\right)$, or $\mathrm{B}_{\mathrm{T}}-\mathrm{A}_{\mathrm{T}}=\mathrm{A}_{\mathrm{T}}-\mathrm{C}_{\mathrm{T}}$ where the difference between tallies of ad|acently ranked candidates agree.

To provide a further sense of how to interpret Theorem 3, consider the $\left(\begin{array}{lll}6 & 5 & 3 \\ 1 & 4 & 2\end{array}\right)$ ranked data with its $\frac{2}{3} \tilde{\mathrm{C}}_{\mathrm{A}}-\frac{4}{3} \tilde{\mathrm{C}}_{\mathrm{B}}+\frac{2}{3} \tilde{\mathrm{I}}_{\mathrm{A}}+\frac{4}{3} \tilde{\mathrm{R}}+\frac{4}{3} \mathrm{~K}$ decomposition. The core term coefficients determine the Kruskal-Wallis ranking (Prop. 4) where, $b_{C}=\frac{4}{3}>a_{C}=\frac{2}{3}>0$, so the KruskalWallis ranking is $\mathrm{B} \succ \mathrm{A} \succ \mathrm{C}$ where the difference between the $\mathrm{B}$ and $\mathrm{A}$ tallies equals the difference between the $\mathrm{A}$ and $\mathrm{C}$ tallies. Because all $\mathrm{P}_{\mathrm{s}}$ tallies agree on the core components and because this common core tally is the Kruskal-Wallis tally (minus kernel effects), the Kruskal-Wallis ranking serves as our standard basis for comparison. The relatively large rotational coefficient of this decomposition, $r=\frac{4}{3}$, suggests that the pair wise rankings may not agree with KruskalWallis ranking: They do not, a computation (using Prop. 4) proves that this data set has a $\mathrm{A}=\mathrm{B}, \mathrm{A}=\mathrm{C}$ tie with $B \succ C$. Moreover, the A-inversion value of $a_{I}=\frac{4}{3}$ suggests that the Bhapkar $\mathrm{V}$ ranking (in our notation, $\mathrm{NP}_{0}(\mathrm{~d})$ ) might differ from the Kruskal-Wallis ranking, it does with $\mathrm{A}=\mathrm{B} \succ \mathrm{C}$. At the other extreme, the $\mathrm{NP}_{1}(\mathrm{~d})$ ranking differs from the Kruskal-Wallis outcome in a different direction, it is $\mathrm{B} \succ \mathrm{A}=\mathrm{C}$. The earlier assertion that all $\mathrm{NP}_{\mathrm{s}}(\mathrm{d})$ outcomes define a line with endpoints $\mathrm{NP}_{0}(\mathrm{~d})$ and $\mathrm{NP}_{1}(\mathrm{~d})$ ensures that all remaining $\mathrm{NP}_{\mathrm{s}}(\mathrm{d})$ rankings are $\mathrm{A} \succ \mathrm{B} \succ \mathrm{C}$, but their tallies differ due to the inversion components of $G(d)$.

On the other hand, the $\left(\begin{array}{lll}6 & 5 & 4 \\ 2 & 3 & 1\end{array}\right)$ ranked data has the $\tilde{\mathrm{C}}_{\mathrm{A}}+\tilde{\mathrm{C}}_{\mathrm{B}}-\frac{1}{3} \tilde{\mathrm{I}}_{\mathrm{B}}+\frac{4}{3} \mathrm{~K}$ decomposition. The core terms define the Kruskal-Wallis ranking of $\mathrm{A}=\mathrm{B} \succ \mathrm{C}$ where the absence of a rotational term ensures that this ranking and the tallies agree with those of the pair wise comparisons of $\mathrm{A}=\mathrm{B}, \mathrm{A} \succ \mathrm{C}, \mathrm{B}$. The inversion term requires the Bhapkar $\mathrm{V}$ tally and ranking to penalize $\mathrm{B}$, which it does with the ranking $\mathrm{A} \succ \mathrm{B} \succ \mathrm{C}$.

Characterizing data sets: Different rules react differently to different kinds of data sets, so the next step is to characterize which data sets (for $n \geq 2$ ) strictly define kernel, rotational and inversion terms. While the natural approach is to use the inverse $\mathrm{G}^{-1}$ mapping, this is not feasible. As an alternative, properties of what would be the $\mathrm{G}^{-1}$ sets are determined. So, to create examples that exhibit more general behavior, just combine these structures. (Some care is needed because of the inherent sense of nonlinearity of $\mathrm{G}(\mathrm{d})$, i.e., in general, $G\left(d_{1} \cup d_{2}\right)$ does not equal $G\left(d_{1}\right)+G\left(d_{2}\right)$.

Definition 2: A ranked data set $d$ is called a kernel, inversion, rotational, core data set if and only if $G(d)$ is, respectively, a kernel configuration, the sum of a kernel and (nonzero) inversion configuration, the sum of a kernel and (nonzero) rotational configuration, the sum of a kernel and(nonzero) core configuration.

The characterization of the disruptive rotational and inversion components of the data is straightforward. The difficulty is to prove that such data examples exist. In the following characterization, let $\mathrm{XYZ}$ be the set of all triplets constructed from the ranked data of the Eq. 1 form that have the ranking $\mathrm{X} \succ \mathrm{Y} \succ \mathrm{Z}$ and let $|\mathrm{XY} \mathrm{Z}|$ be the number of such triplets. Similarly, $X Y$ are all triplets that have $X$ ranked above $\mathrm{Y}$ and $|\mathrm{XY}|$ is the number of such triplets. Proofs of the following results are in the Appendix.

Particular interest is in the inversion behavior as it forces different $\mathrm{NP}_{\mathrm{s}}$ outcomes.

Theorem 5: Data set $d$ is a strict inversion data set if and only if:

$|\mathrm{ABC}|=|\mathrm{CBA}|,|\mathrm{ACB}|=|\mathrm{BCA}|,|\mathrm{CAB}|=|\mathrm{BAC}|$ 
where, at least two sets of equalities do not have the same value and:

$$
|\mathrm{AB}|=|\mathrm{BC}|=|\mathrm{CA}|=|\mathrm{BA}|=|\mathrm{CB}=| \mathrm{AC} \mid
$$

Such data sets exist: Examples seem to require the $\mathbb{Z}_{2}$ orbit structure whereby rows have opposing rankings. This is the structure of the Eq. 4 example, which is a pure inversion data set. Also, for the pure inversion:

$$
\begin{array}{ccc}
\text { A } & \text { B } & \text { C } \\
12 & 11 & 10 \\
7 & 9 & 8 \\
6 & 4 & 5 \\
1 & 2 & 3
\end{array}
$$

the first and fourth rows and the second and third rows reverse each other. However, examples exist that do not have the same number of rows with one ranking as with its reversal. A two-sample reversal example is where the A, B ranked information is $(1,3),(2,4),(6,5),(8$, $7),(10,9),(12,11)$ where the first four rows have $\mathrm{A}>$ B while the last two have B > A. Three alternatives examples also can be created.

Rotational data sets are interesting because they create pair wise cycles and differences between pair wise rankings and all $\mathrm{NP}_{\mathrm{s}}$ outcomes.

Theorem 6: Data set $d$ is a strict rotational data set if and only if:

$|\mathrm{ABC}|=|\mathrm{BCA}|=|\mathrm{CBA}| \neq|\mathrm{ACB}|=|\mathrm{CBA}|=|\mathrm{BAC}|$

if and only if:

$|\mathrm{AB}|=|\mathrm{BC}|=|\mathrm{CA}| \neq|\mathrm{BA}|=|\mathrm{CB}|=|\mathrm{AC}|$

$|\mathrm{ABC}+| \mathrm{ABC}|=| \mathrm{BAC}|+| \mathrm{BCA}|=| \mathrm{CAB}|+| \mathrm{CBA} \mid=\frac{\mathrm{n}^{3}}{3}$

and for any permutation of the letters:

$$
\begin{aligned}
& \mathrm{ABC}|\mathrm{ACB}|+\frac{1}{2}(|\mathrm{CAB}|+|\mathrm{BAC}|)= \\
& |\mathrm{BAC}|+|\mathrm{BCA}|+\frac{1}{2}(\mathrm{ABC}|+| \mathrm{CBA} \mid)
\end{aligned}
$$

Such data sets exist: The construction of such data sets captures the spirit of the $\mathbb{Z}_{3}$ structure, but with complications. To explain, the following pure rotational data set is divided into three parts:

$\begin{array}{ccccccccc}\text { A } & \text { B } & \text { C } & \text { A } & \text { B } & \text { C } & \text { A } & \text { B } & \text { C } \\ 27 & 26 & 25 & 16 & 18 & 17 & 8 & 7 & 9 \\ 22 & 24 & 23 & 14 & 13 & 15 & 6 & 5 & 4 \\ 20 & 19 & 21 & 12 & 11 & 10 & 1 & 3 & 2\end{array}$

where, the first array arranges the row data in the expected $\mathrm{A}>\mathrm{B}>\mathrm{C}, \mathrm{B}>\mathrm{C}>\mathrm{A}, \mathrm{C}>\mathrm{A}>\mathrm{B}$ order of a $\mathbb{Z}_{3}$ orbit. The $3^{3}=27$ rankings, however, are $|\mathrm{ABC}|=|\mathrm{CAB}|=5$, $|\mathrm{BCA}|=8$, while $|\mathrm{BAC}|=2,|\mathrm{CBA}|=3$ and $|\mathrm{ACB}|=5$, according to Theorem 10 , the $\mathrm{G}(\mathrm{d})$ ranking is not a pure rotational plus kernel term as it slightly favors C. Nevertheless, the outcome is a pair wise cycle, $\mathrm{A}>\mathrm{B}$, B $>C$ each by $15: 13$ and $C>A$ by $16: 12$.

To create a pure rotational term, introduce two more sets of three rows where the top defining rows among the sets have the $\mathbb{Z}_{3}$ rankings. As the first row of the first set starts with an $A>B>C$ ranking, start the second set with $B>C>A$, where $A$ is slightly favored and the final set with $C>A>B$, where $B$ is slightly favored. Namely, each set of three rows reacts the $\mathbb{Z}_{3}$ symmetry and the three sets are connected with a $\mathbb{Z}_{3}$ symmetry construction. The resulting Eq. 27 is a rotational data set. While all rotational data sets we have found satisfy this construction, we expect other structures will be discovered.

Constructing examples with mixed behavior now is immediate. For instance, the first block below is a version of the first three rows of Eq. 27, the second block is the pure reversal Eq. 3:

$$
\begin{array}{cccccc}
\text { A } & \text { B } & \text { C } & \text { A } & \text { B } & \text { C } \\
15 & 14 & 13 & 6 & 5 & 4 \\
10 & 12 & 11 & 1 & 2 & 3 \\
8 & 7 & 9 & & &
\end{array}
$$

Combined, the new data set has the anticipated outcome with the Kruskal-Wallis ranking $\mathrm{A}=\mathrm{B}=\mathrm{C}$, the $\mathrm{NP}_{\mathrm{s}}$ ranking of $\mathrm{A} \succ \mathrm{B} \succ \mathrm{C}$ for $\mathrm{s}<\frac{1}{2}$ and $\mathrm{C} \succ \mathrm{B} \succ \mathrm{A}$ for $\mathrm{s}>\frac{1}{2}$ and the pair wise rankings for the cycle $\mathrm{A} \succ \mathrm{B}, \mathrm{B} \succ \mathrm{C}, \mathrm{C} \succ \mathrm{A}$. The kernel data sets are characterized by the following.

Theorem 7: Data set $\mathrm{d}$ is a kernel data set if and only if:

$$
|\mathrm{ABC}|=|\mathrm{ACB}|=|\mathrm{CAB}|=|\mathrm{CBA}|=|\mathrm{BCA}|=|\mathrm{BAC}|
$$

if and only if: 


$$
\begin{aligned}
& |\mathrm{AB}|=|\mathrm{BA}|=|\mathrm{CB}|=|\mathrm{BC}|=|\mathrm{AC}|=|\mathrm{CA}| \\
& |\mathrm{ABC}|+|\mathrm{ACB}|=|\mathrm{BAC}|+|\mathrm{BCA}|= \\
& |\mathrm{CAB}|+|\mathrm{CBA}|=\frac{\mathrm{n}^{3}}{3}
\end{aligned}
$$

and for any permutation of the letters:

$$
\begin{aligned}
& |\mathrm{ABC}|+|\mathrm{ACB}|+\frac{1}{2}(|\mathrm{CAB}|+|\mathrm{BAC}|)= \\
& |\mathrm{BAC}|+|\mathrm{BCA}|+\frac{1}{2}(\mathrm{ABC}|+| \mathrm{CBA} \mid)
\end{aligned}
$$

Such data sets exist.

An example is:

$$
\begin{array}{ccc}
\text { A } & \text { B } & \text { C } \\
17 & 16 & 18 \\
14 & 15 & 13 \\
10 & 12 & 11 \\
9 & 7 & 8 \\
6 & 5 & 4 \\
1 & 2 & 3
\end{array}
$$

where, the first two rows have the inversion $C>A>B$, $\mathrm{B}>\mathrm{A}>\mathrm{C}$ assortment, the next two have $\mathrm{B}>\mathrm{A}>\mathrm{C}, \mathrm{C}>\mathrm{A}>\mathrm{B}$ and the last two have $\mathrm{A}>\mathrm{B}>\mathrm{C}, \mathrm{C}>\mathrm{B}>\mathrm{A}$. In other words, a kernel term is created by introducing canceling inversion components. The same construction can be done by combining two canceling rotational terms.

The final step would be to find a pure core data set. We can prove that such data sets do not exist when certain reasonable assumptions are imposed, but, as of this writing, we do not know whether this is true in general. We can, however, find conditions whereby the data set has no core terms, this is true if and only if the Kruskal-Wallis ranking is a complete tie.

Theorem 8: The string of equalities $\mathrm{ABC}|+| \mathrm{ACB} \mid+$ $\frac{1}{2}(|\mathrm{CAB}|+|\mathrm{BAC}|)=|\mathrm{BAC}|+|\mathrm{BCA}|+\frac{1}{2}(\mathrm{ABC}|+| \mathrm{CBA} \mid)=$ $|\mathrm{CBA}|=\frac{1}{2}(|\mathrm{ACB}|+|\mathrm{BCA}|)$ holds if and only if Kruskal-Wallis technique outputs $\mathrm{A}=\mathrm{B}=\mathrm{C}$. This condition also holds if and only if the sums of the Eq. 1 columns are equal (with value $\frac{\mathrm{n}(3 \mathrm{n}+1)}{2}$ ).

Theorem 9: The equalities $|\mathrm{ABC}|+|\mathrm{ACB}|=$ $|\mathrm{BAC}|+|\mathrm{BCA}|=|\mathrm{CAB}|+|\mathrm{CBA}|=\frac{\mathrm{n}^{3}}{3}$ hold if and only if the $\mathrm{V}$ test outputs $\mathrm{A}=\mathrm{B}=\mathrm{C}$.
Proof of Theorem 2: The first part follows directly from Theorem 1.

The second part follows from Theorem 1 and Eq. $14, \mathrm{NP}_{\mathrm{s}}$ rankings are determined by core and inversion terms in $\mathrm{G}(\mathrm{d})$. If any two different $\mathrm{NP}_{\mathrm{s}}$ methods have complete ties, it follows from Eq. 13 that $\mathrm{G}(\mathrm{d})$ has no core or inversion components. Thus all $\mathrm{NP}_{\mathrm{s}}$ rules define a complete tie and G(d) consists of kernel and rotation terms. If one pair wise outcome is not a tie, then $G(d)$ has a non-zero rotation component. Consequently (Eq. 12), the pair wise comparisons define a cycle and the differences between tallies of the three pairs is fixed.

For the third part, the fact that all pair wise comparisons end in ties means that $\mathrm{G}(\mathrm{d})$ does not have any core or rotational terms. In turn, the Kruskal-Wallis ranking is a complete tie (Theorem 1). Thus, $\mathrm{G}(\mathrm{d})$ is the sum of a kernel and inversion terms. It follows from Eq. 13 that the $\mathrm{NP}_{s}(\mathrm{~d})$ tallies define a line in $\mathrm{R}^{3}$ where $\mathrm{NP}_{\frac{1}{2}}(\mathrm{~d})$ is a complete tie that is on the diagonal $\mathrm{t}(1,1$, 1). It follows from the geometry of $\mathrm{R}^{3}$, as divided by the hyperplanes $\mathrm{x}=\mathrm{y}, \mathrm{x}=\mathrm{z}, \mathrm{y}=\mathrm{z}$, that all points on line that are on one side of $s=\frac{1}{2}$ have the same ranking,

while those with $s>\frac{1}{2}$ have the opposite ranking.

Proof of Theorem 3: This is a direct computation. After computing $\mathrm{G}(\mathrm{d})$ for each data set, the decomposition comes from using Eq. 17.

Proofs of Theorem 5-7. The "if and only if" assertions involving Eq. 21-29 follow directly from properties $G(d)$ must satisfy for $d$ to have the designated properties. In practice, we found that one or the other of these conditions, depending on the data set, to be more useful when examining data.

While the existence assertion in each of these theorems is verified by finding examples, the way in which examples were found and theorems proved (independent of finding examples) was to verify the necessary and sufficient conditions of each of these theorems by proving that the $\mathrm{G}(\mathrm{d})$ mapping admits the specified properties. The details for Theorems 5 and 7 are given next, details for Theorem 6 are similar.

Lemma 1: Let the $\mathrm{n} \times 3$ data set $\mathrm{d}$ have distinct entries $\left(a_{1}, . ., a_{n}, b_{1}, . .\right.$, bn, $\left.c_{1} . ., c_{n}\right)$, then $|A B|+|B A|=|B C|+$ $|\mathrm{CB}|=|\mathrm{AC}|+|\mathrm{CA}|=\mathrm{n}^{2}$.

Proof: Let AB be the set of all elements of the $\left(a_{i}, b_{j}\right)$ form where $a_{i}>b_{j}$, so BA denotes the set of the form (ai, $b$ ) where $a_{i}<b_{j}$. Thus $A B+B A$ is the set of all elements $\left(a_{i}, b_{j}\right)$, by counting, there are exactly $n^{2}$ of these types of elements. This completes the proof. 
This following Lemma highlights the importance of the pair wise relationship in the data, while providing an appropriate structure to capture the Reversal data behavior.

Lemma 2: The equality $|\mathrm{ABC}|=|\mathrm{CBA}|$ holds if and only if $|B A|+|C B|=n^{2}$ if and only if $|A B|+|B C|=n^{2}$.

Proof: By definition $|\mathrm{ABC}|$ is the number of triplets of the form $a_{i}>b_{j}>c_{k}$. This number can be expressed in terms of pair wise relationship between $\mathrm{A}$ and $\mathrm{B}$ and between $B$ and $C$. In other words, defining $A b_{j} C=\left\{\left(a_{i}\right.\right.$, $\left.\left.b_{j}, c_{k}\right) \mid 1 \leq i, k \leq n: a_{i}>b_{j}>c_{k}\right\}$ (i.e., $b_{j}$ is fixed), we have that $|A B C|=\sum_{j=1}^{n}\left|A b_{j} C\right|$. By letting $A b_{j}=\left\{\left(a_{i}, b_{j}\right)|1 \leq i| \leq\right.$,$n :$ $\left.a_{1}>b_{j}\right\}$ (i.e., $b_{j}$ is fixed), this sum can be re-expressed as $\sum_{j=1}^{n}\left|A b_{j} C\right|\left|b_{j} C\right|$.

To simplify this expression, notice that with $n$ entries per column, the number of pairs of the $\left|A b_{j}\right|$ form equals $\left(n-\left|b_{j} A\right|\right)$. The reason is that the pairs $A b_{j}$ consist of the A's (out of the n total number of A's) that are larger than $b_{j}$ for a fixed. Thus the remaining A's (out of $\mathrm{n}$ of them) must be smaller than $b_{j}$. Consequently, we have that $\sum_{j=1}^{n}\left|A b_{j} C\right|\left|b_{j} C\right|=\sum_{j=1}^{n}\left(n-\mid b_{j} A\right)\left(n-\left|C b_{j}\right|\right)$.

By factoring, this sum equals $\sum_{\mathrm{j}=1}^{\mathrm{n}}\left|\mathrm{n}^{2}-\mathrm{n}\right| \mathrm{Cb} \mathrm{b}_{\mathrm{j}}|-\mathrm{n}| \mathrm{b}_{\mathrm{j}} \mathrm{A}|+| \mathrm{Cb}_{\mathrm{j}}\left|\mathrm{b}_{\mathrm{j}} \mathrm{A}\right|=\mathrm{n}^{3}-\mathrm{n}|\mathrm{BA}|-\mathrm{n}|\mathrm{CB}|$ $+\left[\sum_{\mathrm{j}=1}^{\mathrm{n}} \mid \mathrm{Cb} b_{\mathrm{j}} \mathrm{A}\right]=\mathrm{n}^{3}-\mathrm{n}|\mathrm{BA}|-\mathrm{n}|\mathrm{CB}|=0$. In turn, we have that $n^{3}-n|B A|-n|C B|+|C B A|=|C B A|$ if and only if $n^{3}-n|B A|-n|C B|=0$ and this only happens if and only if $|\mathrm{BA}|+|\mathrm{CB}|=\mathrm{n}^{2}$. This completes the proof.

Lemma 3: The equality $|\mathrm{ABC}|=|\mathrm{CBA}|$ holds if and only if $|\mathrm{AB}|=|\mathrm{CB}|$ if and only if $|\mathrm{BA}|=|\mathrm{BC}|$.

Proof: From Lemma 1 we have that $|A B|+|B A|=n^{2}=$ $|\mathrm{CB}|+|\mathrm{BC}|$. According to Lemma 2, $|\mathrm{ABC}|=|\mathrm{CBA}|$ holds if and only if $|\mathrm{AB}|+|\mathrm{BC}|=\mathrm{n}^{2}$ if and only if $\mathrm{n}^{2}=$ $|\mathrm{CB}|+|\mathrm{BA}|$. So, if $|\mathrm{ABC}|=|\mathrm{CBA}|$, then the two equations $|\mathrm{AB}|+|\mathrm{BA}|=\mathrm{n}^{2}$ and $|\mathrm{AB}|+|\mathrm{BC}|=\mathrm{n}^{2}$ require $|\mathrm{BA}|=|\mathrm{CB}|$, similarly, $|\mathrm{AB}|=|\mathrm{BC}|$. Conversely, if $|\mathrm{AB}|=$ $|\mathrm{CB}|$, then the $|\mathrm{AB}|+|\mathrm{BA}|=\mathrm{n}^{2}$ expression becomes $|\mathrm{CB}|+|\mathrm{BA}|=\mathrm{n}^{2}$. According to Lemma 2, this is true if and only if $|\mathrm{ABC}|=|\mathrm{CBA}|$ if and only if $|\mathrm{AB}|+|\mathrm{BC}|=$ $\mathrm{n}^{2}$. A similar argument holds if $|\mathrm{BA}|=|\mathrm{BC}|$.

Lemma 4: The equalities $|\mathrm{ABC}|=|\mathrm{CBA}|,|\mathrm{BCA}|=$ $|\mathrm{ACB}|$ and $|\mathrm{CAB}|=|\mathrm{BAC}|$ hold if and only if $|\mathrm{AB}|=$ $|\mathrm{BA}|=|\mathrm{CA}|=|\mathrm{CB}|=|\mathrm{BC}|=|\mathrm{CB}|$.
Proof: By Lemma 3, $|\mathrm{ABC}|=|\mathrm{CBA}|$ if and only if $|\mathrm{AB}|$ $=|\mathrm{CB}|$ if and only if $|\mathrm{BA}|=|\mathrm{BC}|$. This implies that $|\mathrm{ACB}|=|\mathrm{BCA}|$ if and only if $|\mathrm{AC}|=|\mathrm{BC}|$ if and only if $|\mathrm{CA}|=|\mathrm{CB}|$ and $|\mathrm{CAB}|=|\mathrm{BAC}|$ if and only if $|\mathrm{CA}|=$ $|\mathrm{BA}|$ if and only if $|\mathrm{AC}|=|\mathrm{AB}|$. Then $|\mathrm{ABC}|=|\mathrm{CBA}|$, $|\mathrm{BCA}|=|\mathrm{ACB}|$ and $|\mathrm{CAB}|=|\mathrm{BAC}|$ if and only if $|\mathrm{AC}|=$ $|\mathrm{BC}|,|\mathrm{CA}|=|\mathrm{CB}|,|\mathrm{CAB}|=|\mathrm{BAC}|,|\mathrm{CA}|=|\mathrm{BA}|,|\mathrm{AC}|=$ $|\mathrm{AB}|$ and $|\mathrm{CA}|=|\mathrm{CB}|$ which imply $|\mathrm{AB}|=|\mathrm{BA}|=|\mathrm{CA}|=$ $|\mathrm{CB}|=|\mathrm{BC}|=|\mathrm{CB}|$.

Proof of Theorem 5: This follows from the definition of an inversion data set and Lemma 4. Theorem 7 also follows from the above lemmas.

Proof of Theorem 8: The Kruskal-Wallis technique, $\mathrm{NP}_{\frac{1}{2}}$, assigns one, $1 / 2$ and zero points, respectively, to the first, second and third place alternative in a triplet. Thus $\mathrm{A}=\mathrm{B}=\mathrm{C}$ if and only if for any alternative the number triplets it wins plus half of the number of the triplets it is in second place is the same value. Namely, $|\mathrm{ABC}|+|\mathrm{ACB}|+\frac{1}{2}(|\mathrm{CAB}|+|\mathrm{BAC}|)$ $=|\mathrm{BAC}|+|\mathrm{BCA}|+\frac{1}{2}(|\mathrm{ABC}|+|\mathrm{CBA}|)=|\mathrm{CAB}|+|\mathrm{CBA}|+$ $\frac{1}{2}(|\mathrm{ACB}|+|\mathrm{BCA}|)$. An alternative Kruskal-Wallis procedure is to add the Eq. 1 columns. The procedure has a tie if and only if these sums all agree. As the values from 1 to $3 n$ sum to $\frac{3 n(3 n+1)}{2}$, the common value is $\frac{n(3 n+1)}{2}$.

Proof of Theorem 9: The $\mathrm{V}$ test technique, $\mathrm{NP}_{0}$, assigns one point to the winner of each triplet and zero points to the second and third place alternatives. For the $\mathrm{V}$ test to have $\mathrm{A}=\mathrm{B}=\mathrm{C}$, the number of triplets for which each alternative is top-ranked is the same, or $|\mathrm{ABC}|+|\mathrm{ACB}|=|\mathrm{BAC}|+|\mathrm{BCA}|=|\mathrm{CAB}|+|\mathrm{CBA}|$. With $\mathrm{n}^{3}$ triplets when each alternative has $n$ observations, the triplets are divided into three equal parts, so $|\mathrm{ABC}|+|\mathrm{ACB}|=|\mathrm{BAC}|+|\mathrm{BCA}|=|\mathrm{CAB}|+|\mathrm{CBA}|=\frac{\mathrm{n}^{3}}{3}$.

\section{CONCLUSION}

Inconsistencies among the outcomes of nonparametric procedures can occur when analyzing the same ranked data set. Understanding why these peculiarities can occur is imperative to providing an accurate and desired analysis of ranking data. The results in this study illustrate that the inconsistency of procedure outcomes can be attributed to specific symmetric data structures that may be present in the 
data. These findings thus offer a comprehensive analysis of the problem by: (1) defining the symmetric structures that cause the inconsistent outcomes, (2) developing a method to uncover the existence of the symmetric structures in a data set, (3) understanding the effects of each type of symmetric structure on each nonparametric procedure and (4) characterizing data that possess such symmetric structures. This contribution paints a full picture of the issues that may occur when using the nonparametric procedures considered. In addition, it offers a guide for choosing a procedure to analyze ranking data contingent on the importance the researcher wants to place on specific aspects of the data.

\section{REFERENCES}

Bhapkar, V.P., 1961. A nonparametric test for the problem of several samples. Ann. Math. Stat., 32: 1108-1117. DOI: 10.1214/aoms/1177704849

Bhapkar, V.P. and J.V. Deshpande, 1968. Some nonparametric tests for multisample problems. Technometrics, 10: 578-585. DOI: $10.2307 / 1267111$
Deshpande, J.V., 1970. A Class of multisample distribution-free tests. Ann. Math. Stat., 41: 227-236. DOI: $10.1214 /$ aoms/1177697204

Haunsperger, D.B., 1992. Dictionaries of paradoxes for statistical tests on k samples. J. Am. Stat. Assoc., 87: 149-155. DOI: $10.2307 / 2290463$

Kruskal, W.H. and W.A. Wallis, 1952. Use of ranks in one-criterion variance analysis. J. Am. Stat. Assoc., 47: 583-612. DOI: $10.2307 / 2280779$

Saari, D.G., 2008. Disposing Dictators, Demystifying Voting Paradoxes. 1st Edn., Cambridge University Press, New York, ISBN: 10: 0521731607, pp: 256.

Wilcoxon, F., 1945. Individual comparisons by ranking methods. Biomet. Bull., 1: 80-83. DOI: 10.2307/3001968 